\title{
Article \\ The Use of Cold Spraying and Micro-Arc Oxidation Techniques for the Repairing and Wear Resistance Improvement of Motor Electric Bearing Shields
}

\author{
Yury Kuznetsov ${ }^{1}$, Igor Kravchenko ${ }^{2,3} \mathbb{D}$, Dmitry Gerashchenkov ${ }^{4} \mathbb{D}$, Mikhail Markov ${ }^{4}, \operatorname{Vadim}$ Davydov $^{5,6}$, \\ Anna Mozhayko ${ }^{5, *(D)}$, Valentin Dudkin ${ }^{7}$ (D) and Alina Bykova ${ }^{4}$
}

1 Department of Reliability and Repair of Machines, Faculty of Agricultural Engineering and Energy Supply, Orel State Agrarian University Named after N.V. Parakhin, 302019 Orel, Russia; kentury@yandex.ru

2 Department of Technical Service of Machines and Equipment, Russian State Agrarian University—Moscow Timiryazev Agricultural Academy (RSAU—MTAA), 127550 Moscow, Russia; kravchenko-in71@yandex.ru

3 Mechanical Engineering Research Institute, Russian Academy of Sciences, 101990 Moscow, Russia

4 NRC “Kurchatov Institute"—CRISM “Prometey", 191015 St. Petersburg, Russia; gda.prometey@mail.ru (D.G.); barca0688@mail.ru (M.M.); bykova.ad@gmail.com (A.B.)

5 Higher School of Applied Physics and Space Technologies, Peter the Great St. Petersburg Polytechnic University, 195251 St. Petersburg, Russia; davydov_vadim66@mail.ru

6 All Russian Research Institute of Phytopathology, 143050 Moscow, Russia

7 Department of Photonics and Communication Lines, Faculty of Infocommunication Networks and Systems, The Bonch-Bruevich St. Petersburg State University of Telecommunication, 193232 St. Petersburg, Russia; vidoodkin@mail.ru

* Correspondence: annaanna-1996@mail.ru

check for updates

Citation: Kuznetsov, Y.; Kravchenko, I.; Gerashchenkov, D.; Markov, M.; Davydov, V.; Mozhayko, A.; Dudkin, V.; Bykova, A. The Use of Cold Spraying and Micro-Arc Oxidation Techniques for the Repairing and Wear Resistance Improvement of Motor Electric Bearing Shields. Energies 2022, 15, 912. https:// doi.org/10.3390/en15030912

Academic Editor: Adolfo Dannier

Received: 2 December 2021

Accepted: 24 January 2022

Published: 27 January 2022

Publisher's Note: MDPI stays neutral with regard to jurisdictional claims in published maps and institutional affiliations.

Copyright: () 2022 by the authors Licensee MDPI, Basel, Switzerland. This article is an open access article distributed under the terms and conditions of the Creative Commons Attribution (CC BY) license (https:// creativecommons.org/licenses/by/ $4.0 /)$.

\begin{abstract}
Reliability is one of the most important requirements for electric motor installations. Bearing assembly is a common source of failure for most electric motors. One of the main reasons for such failures is the wear of the bearing seat of the end shield. This paper presents a combined technology for increasing the durability of the bearing bores of electric motor bearing shields made of aluminum alloys. The technological concept is that a worn-out end-shield bore is firstly restored by supersonic gas-dynamic spraying, and secondly, in order to improve anti-wear properties, it is strengthened by micro-arc oxidation. The adhesion of coatings has been studied, and the wear resistance of the formed coatings has been evaluated. Based on the performed studies, it can be assumed that the service life of the bearing assembly of an electric motor restored by gas-dynamic spraying with the novel technology of micro-arc oxidation in real operating conditions will increase on average by 3-4 times. The developed technology is recommended for repair, maintenance, or other technical services dealing with the restoration and hardening of worn-out parts.
\end{abstract}

Keywords: gas-dynamic spraying; micro-arc oxidation; technology; electric motor

\section{Introduction}

Energy development and a number of industries in the modern world have dramatically increased loads on various equipment [1-6]. Operation requirements have changed, especially those for electrical systems and equipment $[1,5,7,8]$. Some aspects of the operation of power and electrical equipment have begun to attract more attention [1,7-9]. One of these is reliability.

Reliability is a fundamental requirement for electric propulsion systems [1,7]. For most electric motors, the bearing assembly is the second most important source of failure (after the winding) [8]. One of the main reasons for such failure is bearing seat wear of the end shield (Figure 1), which occurs because of fretting corrosion and subsequent rotation of bearing rings. 


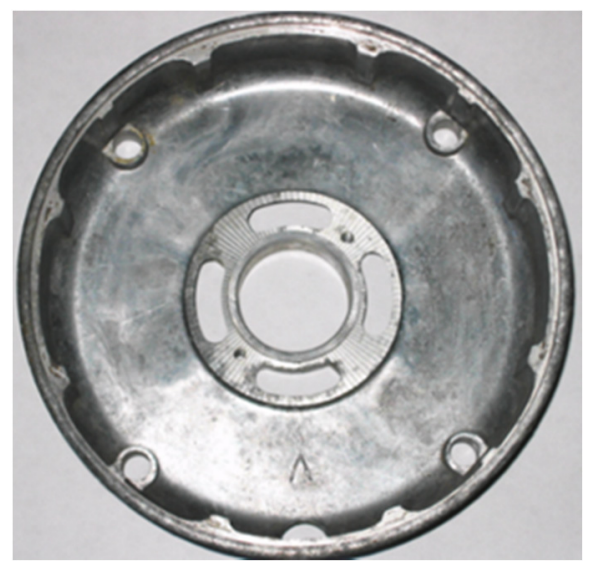

Figure 1. General view of the end shield of an electric motor, outer diameter $30 \mathrm{~cm}$.

At present, the seats of electric motor shield bearings are restored with polymer materials, by thermal spraying, and press fitting of repair bushings.

The Obninsk powder spraying center has developed a fundamentally new method of recovering these parts by supersonic gas-dynamic spraying [9-11], with major advantages such as, environmental friendliness, simplicity, ability to form coatings of a few millimeters, and high adhesion of sprayed coatings to the base (40-80 MPa).

The physical and mechanical properties of coatings formed by cold gas-dynamic spraying are significantly influenced by the air pressure, which serves as a transporting gas of the applied powder material. In the work of many researchers, it is noted that the quality of the formed coatings (adhesion strength and density) can be improved by increasing the speed of the sprayed particles. The gas type, temperature, and pressure, along with the nozzle, control the particle speed [12]. It is well understood that higher gas pressure, higher gas temperature, or lower gas molecular weight causes higher speed of the sprayed particles [13]. In this case, the speed of the sprayed particles can be increased by increasing the pressure $[14,15]$.

An increase in the heating temperature of the carrier gas during cold spraying leads to a decrease in the adhesion strength of the formed coatings [16].

To form coatings by gas-dynamic spraying, powder mixtures based on soft metals (aluminum or copper) are used. Aluminum has the advantages of good ductility, which makes it easy to use aluminum powder for gas-dynamic spraying, as well as high corrosion resistance, low cost, and availability in the market. These advantages make it possible to choose aluminum as a bond coating for the synthesis of a protective coating. However, the final coatings of such materials have low strength and wear resistance. $[17,18]$. As a result, the service life of parts recovered by gas-dynamic spraying, as a rule, is lower than that of new parts. To eliminate these shortcomings, a combined technology of restoration and hardening of the group of parts is proposed. The core fact is that a worn-out end-shield bore is first restored by supersonic gas-dynamic spraying, and then, in order to improve anti-wear properties, it is strengthened by micro-arc oxidation (MAO) [19-21].

The MAO technology has significant advantages over most other methods of surface treatment of aluminum alloys:

- It is nontoxic and environmentally friendly;

- It allows application of coatings to products of any configuration;

- It does not require special preliminary preparation, cleaning, or washing;

- It retains the shape and dimensions of the part during the formation of the coating;

- It is carried out at low temperatures, which does not lead to the deformation of products.

At the same time, MAO coatings have outstanding properties, such as high hardness, wear resistance, corrosion resistance, heat resistance, and high adhesive and cohesive strength. 
Combined technologies, including the restoration of worn-out working surfaces of parts by various methods with subsequent hardening treatment of their outer layer, make it possible to increase the durability of movable joints; therefore, more attention has been recently drawn to different approaches to implement these technologies and their capabilities [22-26].

\section{Object and Research Methodology}

Gas-dynamic spraying (GDS) was performed on the metal coating system DIMET-403 (Figure 2) using aluminum powder A-80-13, consisting of aluminum and containing a technological additive of zinc, which prevents the deposition of material inside the nozzle. The coatings were applied at a temperature of $200-600^{\circ} \mathrm{C}$ and a pressure of $0.5-0.9 \mathrm{MPa}$.

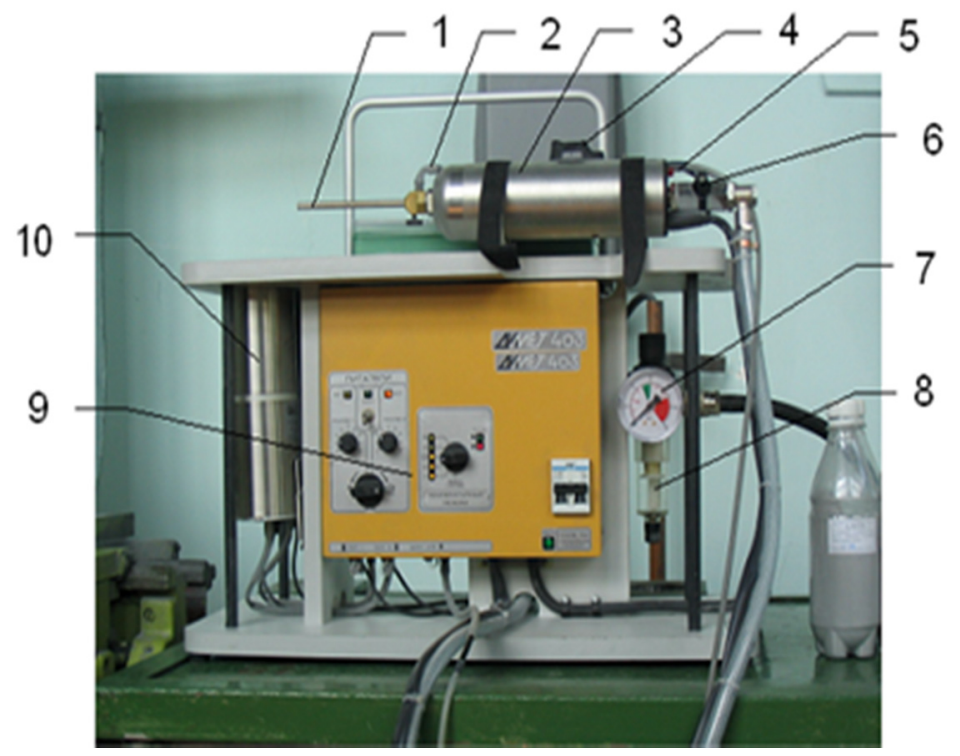

Figure 2. Metal coating system "DIMET-403": 1-nozzle; 2-silicone adapter; 3-sprayer; 4-powder feed button; 5-powder feed tube; 6-pneumatic valve; 7-manometer; 8-filter, 9-control and monitoring unit BKU-03; and 10—feeder PV-43.

The spraying equipment set consisted of the following main parts (Figure 2).

The control and management unit (9) combined in its housing the elements of the power supply of the spray gun (10), the air temperature control system, the power supply system, the control of the powder consumption of the PV-43 feeders, the switch of the powder route, and the switching elements.

The DM-43 sprayer consisted of a supersonic nozzle directly connected to an air heating unit. The supersonic nozzle is the main element that ensures the acceleration of particles to high speeds, leading to the formation of a coating. The inner planes of the nozzle, which are most susceptible to wear during operation, were made in the form of replaceable nozzles, which make it easy to restore the characteristics of the nozzle when it is worn out.

The air heating unit in the sprayer provides heating and stabilization of the temperature of the carrier gas at the inlet to the nozzle, which makes it possible to increase the flow rate while maintaining the nozzle configuration.

The powder feeding device (PV-43) is a self-contained unit that provides uniform dosed movement of the powder loaded into it into the air flow of a supersonic nozzle. The operation of this unit is based on a vibration method for creating the fluidity of powder materials.

The chemical agents used for MAO were as follows: potassium hydroxide (GOST 24363 rev.1) and liquid glass (GOST 130078) with module $m=3.0$ and density $\rho=1.47 \mathrm{~g} / \mathrm{cm}^{3}$. 
The coatings were formed in electrolyte of " $\mathrm{KOH}-\mathrm{Na}_{2} \mathrm{SiO}_{3}$ " type at the following modes: $D_{\mathrm{T}}=18 \mathrm{~A} / \mathrm{dm}^{2} ; t=120 \mathrm{~min}$; electrolyte: $C_{\mathrm{KOH}}=1 \mathrm{~g} / \mathrm{L}, C_{\mathrm{Na} 2 \mathrm{SiO} 3}=8 \mathrm{~g} / \mathrm{L}$.

The samples were oxidized in equipment for the process of micro-arc oxidation, which is a current source, one outlet of which was attached to a part placed in an electrolyte (anode), and the other was attached to a working bath filled with electrolyte (cathode). A cooling system was used to maintain the electrolyte temperature in the required range.

Table 1 shows the modes of formation of coatings.

Table 1. Efficient modes of coating formation.

\begin{tabular}{ccc}
\hline o & Parameter & Value \\
& Modes of supersonic gas-dynamic spraying of coatings & 0.5 \\
1 & Compressed air pressure, $\mathrm{MPa}$ & 0.3 \\
2 & Compressed air consumption, $\mathrm{m}^{3} / \mathrm{min}$ & $200-450$ \\
4 & Compressed air heating temperature, ${ }^{\circ} \mathrm{C}$ & $40-60$ \\
5 & Powder size distribution, $\mu \mathrm{m}$ & 10 \\
1 & Standoff distance, mm & 20 \\
3 & Modes of sprayed coatings hardening by MAO & 30 \\
& Current density, A/dm ${ }^{2}$ & $90-120$
\end{tabular}

For the study, we used aluminum alloys AK12, AK7ch, and G-A1Si12, which are widely used for the manufacture of bearing shields for electric motors [2]. The chemical composition of the alloys is shown in Table 2.

Table 2. The chemical composition of the used aluminum alloys.

\begin{tabular}{ccccccc}
\hline \multirow{2}{*}{ Alloy Grade } & \multicolumn{6}{c}{ Mass Fraction of Main Components (Base-Aluminum), \% } \\
\cline { 2 - 7 } & $\mathbf{M g}$ & $\mathbf{S i}$ & $\mathbf{M n}$ & $\mathbf{C u}$ & $\mathbf{T i}$ & $\mathbf{Z n}$ \\
\hline AK7ch & $0.20-0.40$ & $6.0-8.0$ & 0.50 & 0.20 & - & - \\
AK12 & 0.05 & $11.0-13.0$ & 0.50 & 0.50 & 0.05 & 0.30 \\
G-AlSi12 & $11.0-13.0$ & 0.50 & 0.15 & 0.30 & 0.15 & 0.20 \\
\hline
\end{tabular}

The adhesion of the sprayed layer was determined by the pin method that evaluates the breaking force when the pin is pulled out in the direction normal to its end surface on which the coating was applied (GOST 9.304. Unified system or corrosion and ageing protection. Thermal sprayed coatings. General requirements and methods of control). As a limitation of the use of this method, it can be noted that it is only valid if the coating is completely detached from the pin.

The sample consisted of the pin (Figure 3a) and the washer (Figure 3b) with the gripping device used as a hole for splitting to have an interconnection with the coating layer during spraying. The cylindrical surface of the joined parts with a diameter of $4 \mathrm{~mm}$ was carried out on a sliding fit. The sample was made of aluminum alloy. 

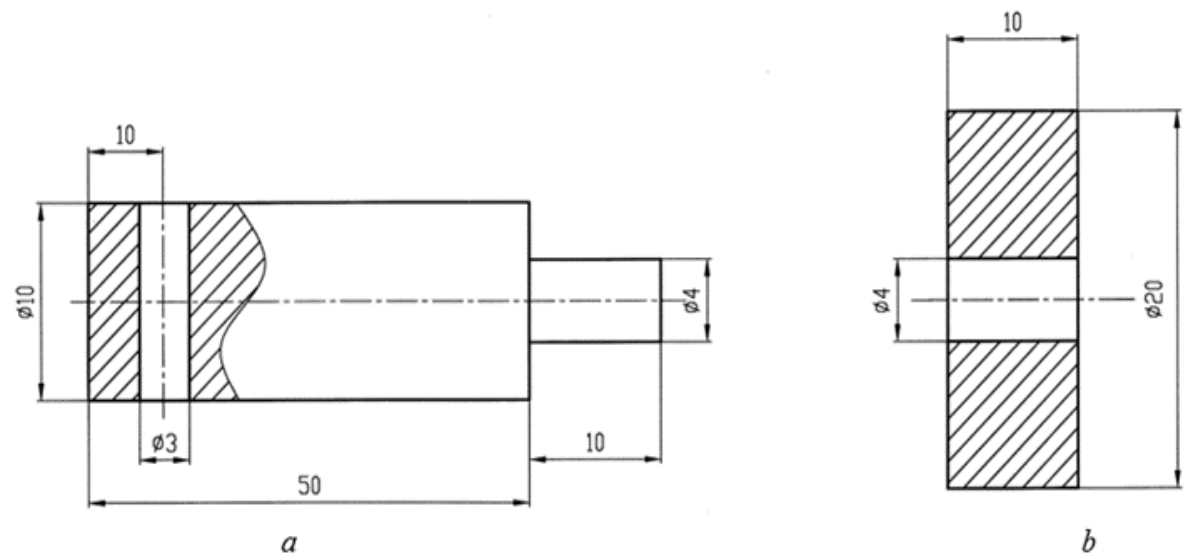

Figure 3. Sample to evaluate the adhesion of the coating and the machined surface: (a) - pin and (b)-washer.

The assembly of pin and washer was installed in the device to fix the sample, and the working surface was ground. The coating was sprayed onto the working surface of the sample with a uniform movement with the following condition:

$$
s=0.77 \ldots 1 d,
$$

where $s$ is the thickness of the sprayed layer, $\mathrm{mm}$ and $d$ is the pin diameter, $\mathrm{mm}$.

The sample was tested on a universal tensile testing machine RM-1000 (LLC "ETsNK" (Unified Center for Non-Destructive Testing, Moscow, Russia).

The tensile strength of the coating was evaluated for each sample by the formula [27]:

$$
P_{a}=(4 \cdot F) /\left(3.14 \cdot d^{2}\right),
$$

where $P_{a}$ is the pull-off stress to evaluate adhesion, MPa; $F$ is the breaking force, $\mathrm{N}$; $d$ is the pin diameter, $\mathrm{mm}$.

The comparative wear resistance of the sample's surface was analyzed with boundary lubrication (as per GOST 23.224-86) on an MTU-01 friction machine (TU 4271-001-290346002004). Aluminum alloys AK12, AK7ch, and G-AlSi12, as well as a sprayed coating without strengthening by MAO were taken as the reference standard. The above alloys served as the material for the manufacture of the lower samples (Figure 4).

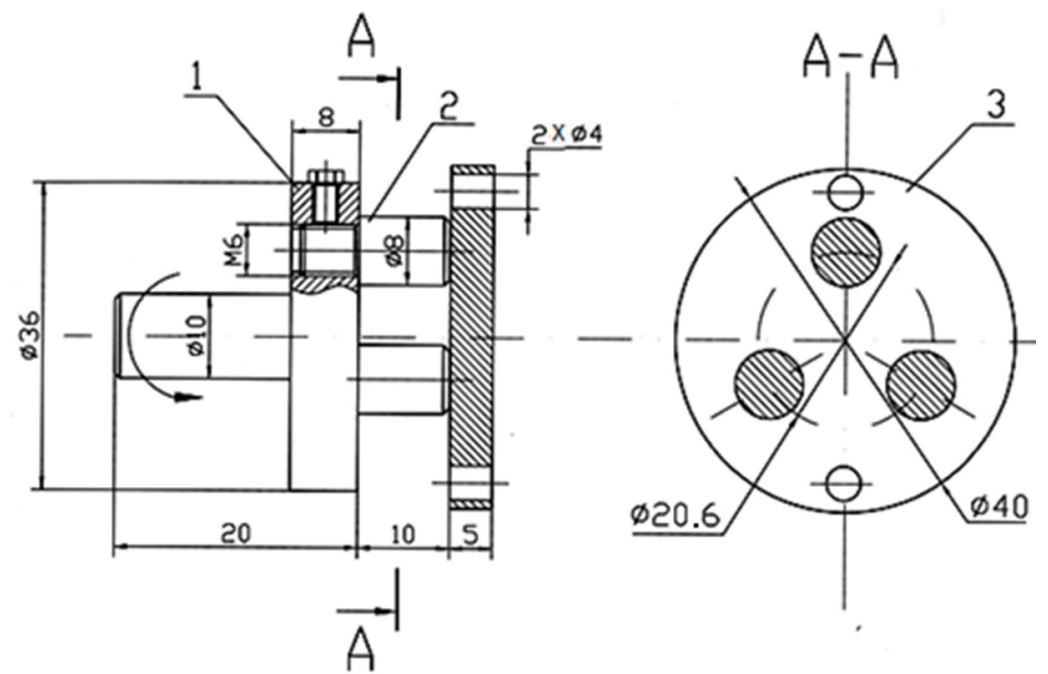

Figure 4. Samples for wear testing: 1-mandrel for upper samples; 2-upper sample; and 3-bottom sample. 
Before $\mathrm{MAO}$, the lower specimen was ground in a mandrel on $3 \mathrm{~B} 722$ surface grinding machine [28]. Then, the lower sample was subjected to MAO in electrolyte for $120 \mathrm{~min}$. Then, the samples were ground with sanding paper to $R_{a}=0.35-0.40 \mu \mathrm{m}$. The upper samples (see Figure 4) of three pieces were made of steel 18KhGT (HRC 58-62) with a contact area of $1.5 \mathrm{~cm}^{2}$ and a roughness of the working surface $R_{a}=0.4 \mu \mathrm{m}$.

A friction pair was used as a reference standard: the lower specimen made of aluminum alloy without coating and the upper specimens of 18KhGT steel (HRC 58-62). The rotating speed of the friction pair was $580 \mathrm{~min}^{-1}$.

The boundary lubrication was made by industrial oil AU (GOST 1642-75) in the friction zone (Figure 5).

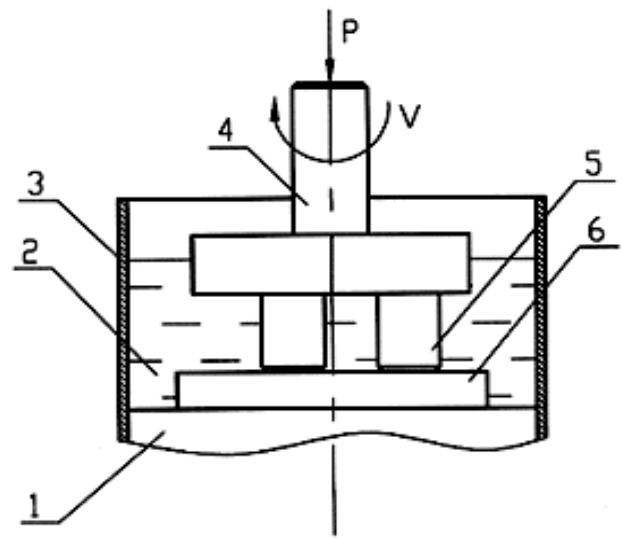

Figure 5. Scheme of wear test samples: 1-base; 2 -lubricant; 3 -protective casing; 4-mandrel for upper samples; 5-upper sample; and 6-bottom sample.

Once the constant value of the friction moment and the run-in of the contact area of the friction pair were fixed at least $90 \%$, the load was increased to the designed level of $1.5 \mathrm{MPa}$ through intervals of $0.25 \mathrm{MPa}$.

The wear of the samples and counterbodies was evaluated by the gravimetric method using VLA-200 scales as per TU 25.06-383-74.

The wear values were recorded every $2 \mathrm{~h}$ of testing with each friction pair tested for $20 \mathrm{~h}$.

The control of materials and agents used for deposition was carried out by nuclear magnetic resonance (NMR), refraction, and atomic-beam spectroscopy [29-33]. These methods enabled obtaining unambiguous data about materials without changing their physical structure and chemical composition. The following equipment was used for measurements: an NMR-spectrometer "X-PULSE" (company "Oxford Instruments", Oxfordshire, UK), a stationary Abbe refractometer "NAR-2T UH" (company “ATAGO”, Tokyo, Japan), and a WDXRF spectrometer "S8 TIGER Series 2" (company "Bruker", Bremen, Germany).

The change in the linear dimensions of the samples during deposition and micro-arc oxidation was monitored with a lever micrometer MP-25, in accordance with the GOST 4381 standard. The measurement accuracy was $\pm 2 \mu \mathrm{m}$. The thickness of the hardened coating layer was also measured on the specimen section using an EC METAM PB-21 metallographic microscope. The measurement error was no more than $1.5 \mu \mathrm{m}$ at $500 \times$.

The microhardness of the coatings was measured on a PMT-3M device in accordance with GOST 9450.

\section{Research Results and Discussion}

In order to select efficient operating modes of the equipment, we studied the coating adhesion and performed comparative wear testing.

Depending on air pressure, the analysis results of the sprayed coatings' adhesion obtained on the AK7ch aluminum alloy showed that the best adhesion of the sprayed material to the base (65 MPa) was achieved with the air pressure of $0.9 \mathrm{MPa}$ (Figure 6). However, in this mode, the unit can operate only briefly and unstably; hence, the best 
way is to have an air pressure of $0.7 \mathrm{MPa}$ in the sputtering block. In this case, the sprayed material adhesion to the base amounted to 58-62 MPa.

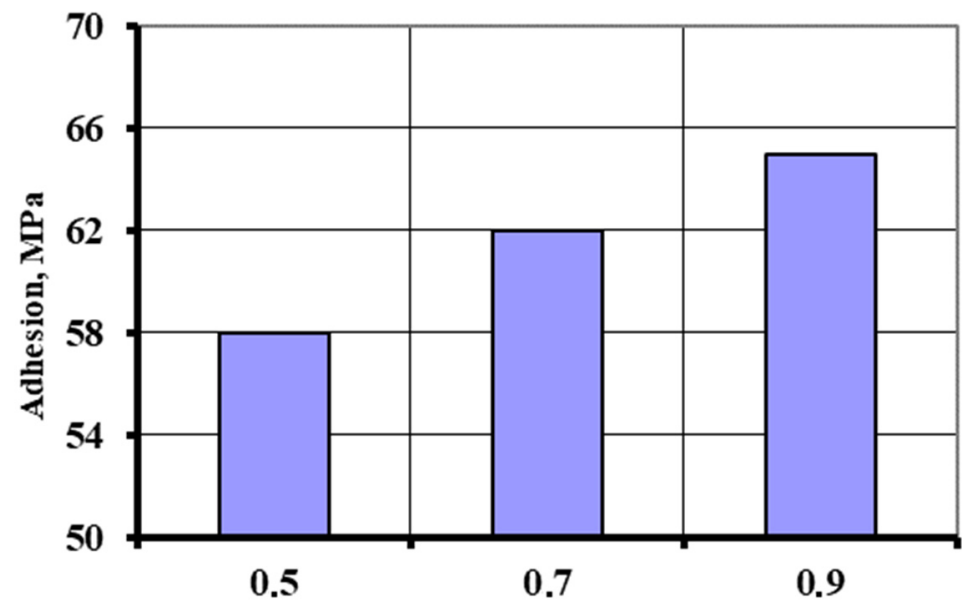

Air pressure in the sputtering block, MPa

Figure 6. Dependence of the coatings' adhesion on air pressure in the sputtering block of RNB. Spraying modes: spraying distance $h=15 \mathrm{~mm}$; air heating temperature in the sputtering block $T=400{ }^{\circ} \mathrm{C}$; and material fraction $f=40 \mu \mathrm{m}$.

When analyzing the sprayed coatings' adhesion, in relation to the temperature of air heating in the spraying block (Figure 7), it was found that the temperature increase lowered the adhesion strength. This occurs if the air temperature increase leads to the increase in the thermodynamic activity of the sprayed particles. Hence, not only will particles with sufficient kinetic energy be fixed on the surface, but also the ones with lower kinetic energy and a higher temperature. This elevates the effective use of the sprayed material with the reduction in the coating adhesion.

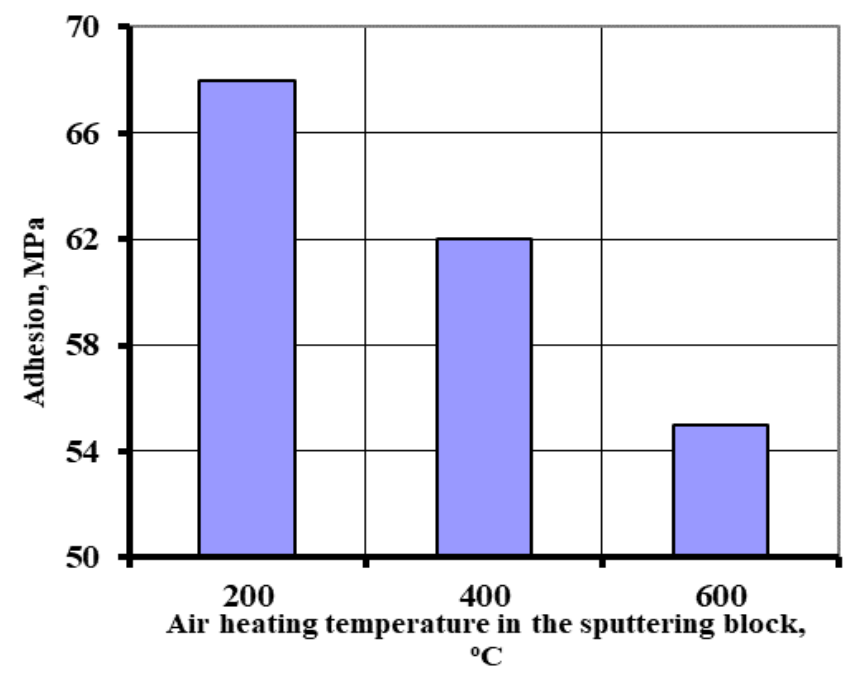

Figure 7. Dependence of the coatings' adhesion on air temperature in the spraying block. Spraying modes: air pressure in the sputtering block $P=0.7 \mathrm{MPa}$; spraying distance $h=15 \mathrm{~mm}$; and material fraction $f=40 \mu \mathrm{m}$.

As can be seen in Figure 7, the maximum adhesion value corresponded to the temperature mode, which led to air heating in the spraying block at about $200{ }^{\circ} \mathrm{C}$. However, the study revealed that in such a temperature mode, there was a low deposition efficiency (4-8\%). When the air temperature in the spraying block reached $400{ }^{\circ} \mathrm{C}$, the utilization rate of the powder reached $12-15 \%$. Therefore, the optimal temperature mode was about $400{ }^{\circ} \mathrm{C}$. 
The results of the obtained data (Figure 8) indicate that the interaction of a solid particle with a base, which occurs during gas-dynamic spraying, depends not only on the heating temperature and air pressure in the sputtering block, but also on the size of the sprayed particle or fractions. For any speed of a particle, there is the size when it bounces off the substrate, even if the maximum possible number of bonds are formed during the contact.

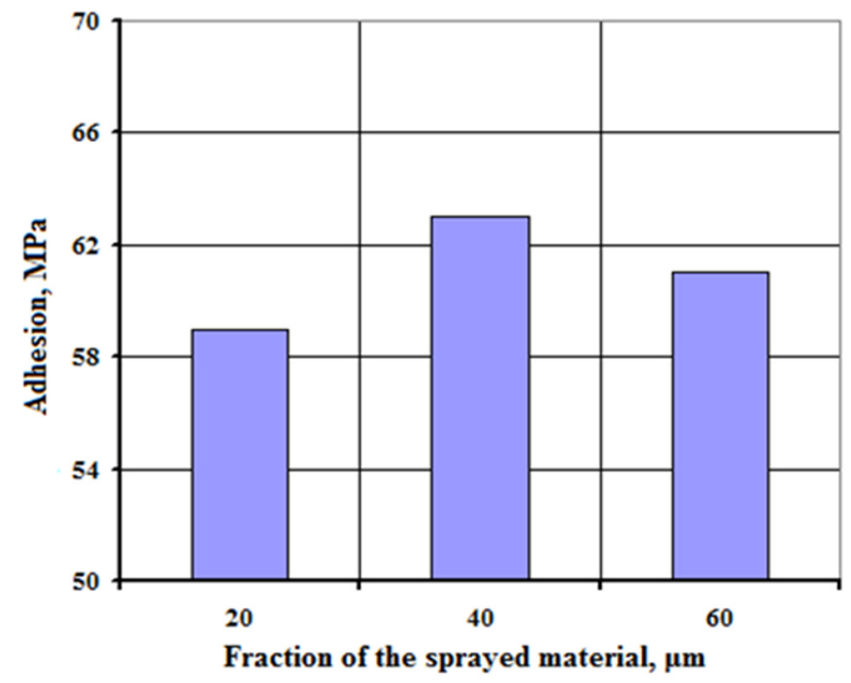

Figure 8. Dependence of the coatings' adhesion on the fraction of the sprayed material. Spraying modes: air pressure $P=0.7 \mathrm{MPa}$; spraying distance $h=15 \mathrm{~mm}$; and air heating temperature $T=400{ }^{\circ} \mathrm{C}$.

Thus, the finding revealed that in the interaction of the particle and the base, the elastic compression energy and the adhesion energy had the same values and, hence, the elastic compression energy played a decisive role in spraying with solid particles. Therefore, to reduce the effect of elastic rebound of a particle, it was necessary to have sufficiently small $(\approx 40 \mu \mathrm{m})$ particles.

The characteristic phase composition of ceramic coatings is determined by the phase of mullite and corundum. There is also a $\mathrm{SiO}_{2}$ compound on the surface of the coatings (Figure 9). During MAO in a silicate-alkaline electrolyte, composite coatings with complex phase composition were formed on the surface of the aluminum base, in which the oxide $\alpha-\mathrm{Al}_{2} \mathrm{O}_{3}$ (corundum) acted as a strengthening phase, providing high microhardness of the coating.

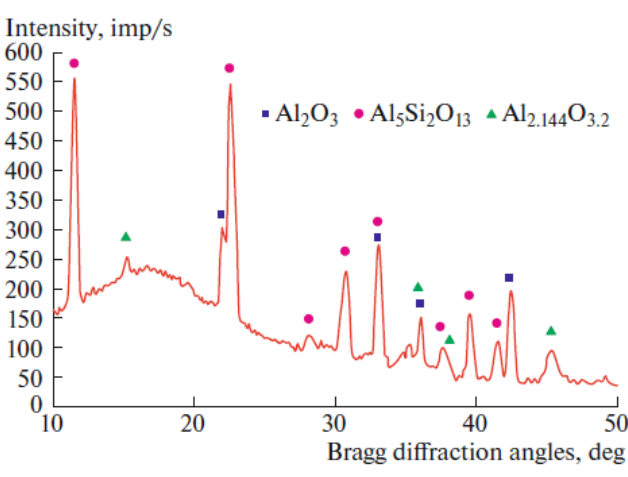

(a)

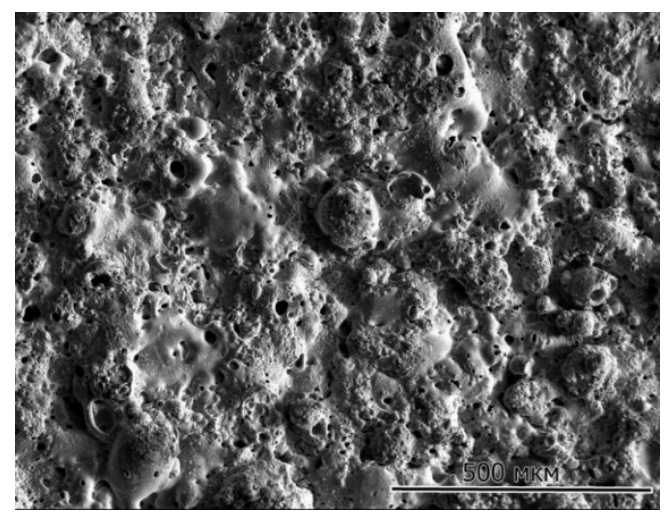

(b)

Figure 9. (a) Typical X-ray of the surface of ceramic coatings. (b) Surface morphology of the relief oxide-ceramic coating. 
The main parameters of the coatings for wear testing are given in Table 3.

Table 3. Main parameters of coatings for wear testing.

\begin{tabular}{cccc}
\hline \multicolumn{2}{c}{ Layer Thickness, $\mathbf{~ m m}$} & \multicolumn{2}{c}{$\begin{array}{c}\text { Microhardness of the Sprayed } \\
\text { Layer, } \mathbf{H V}\end{array}$} \\
\hline $\begin{array}{c}\text { gas-dynamic spraying } \\
0.50-0.51\end{array}$ & hardened by MAO method & before MAO & after MAO \\
& $0.130-0.140$ & $250-280$ & $2965-3185$ \\
\hline
\end{tabular}

The investigation of the wear of the compared friction pairs showed (Figure 10) that the wear had different values depending on the material of the friction pair. The wear tested duration of friction pairs with lower samples of the following composition: aluminum alloys (AK12, AK7ch, G-AlSi12); aluminum alloy (AK7ch) with a coating formed by gasdynamic spraying (powder A-80-13); and aluminum alloy (AK7ch) with a coating formed by gas-dynamic spraying (powder A-80-13) followed by MAO treatment for $20 \mathrm{~h}$.

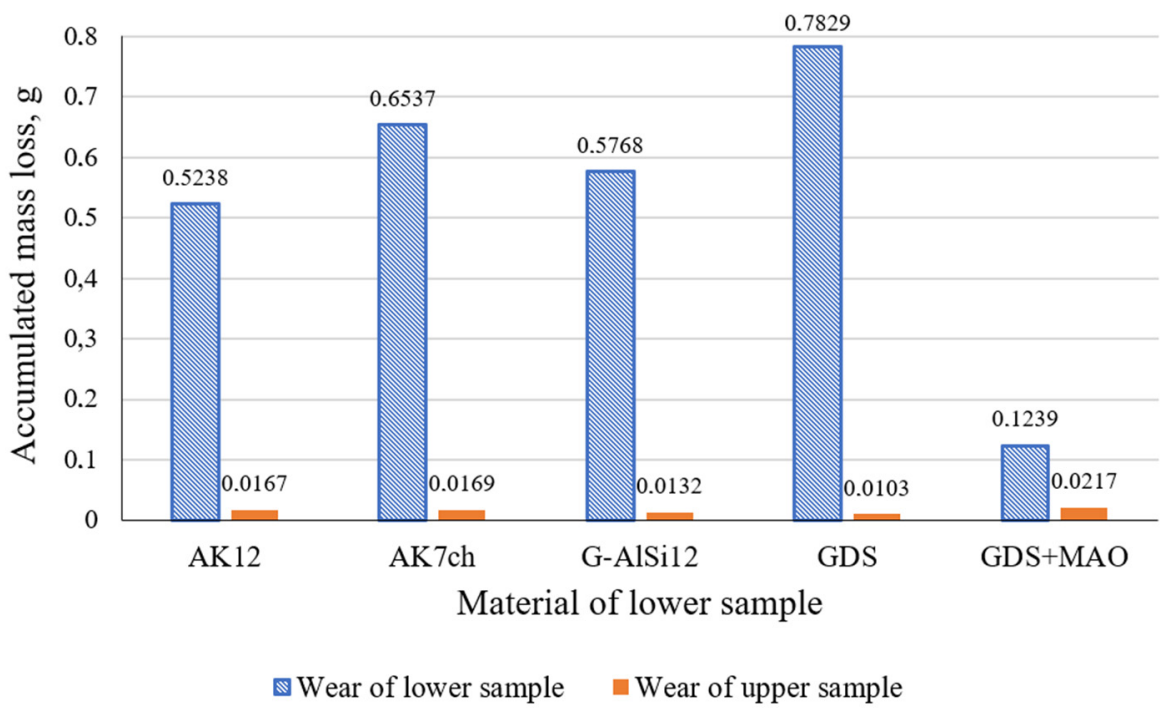

Figure 10. Values of the wear of friction pairs: lower sample (aluminum alloys; coating obtained by gas-dynamic spraying (GDS) (powder A-80-13); coating obtained by gas-dynamic spraying (with powder A-80-13) followed by MAO); upper samples (steel 18HGT).

The wear rate of the coatings formed by gas-dynamic spraying on aluminum alloys from A-80-13 powder with subsequent strengthening by MAO was $0.0062 \mathrm{~g} / \mathrm{h}$. The wear rate of the final coating was several times lower than that of the alloys taken as a reference standard: AK12 alloy—5.13 times, AK7ch alloy-6.41 times, G-AlSi12 alloy-5.67 times, and the coating formed by gas-dynamic spraying-7.68 times.

The developed technology included the following main operations: machining of parts to remove wear marks, abrasive blasting, gas-dynamic spraying, boring, MAO, flushing, drying, and finish machining.

Aluminum surfaces of bored shields of electric motors usually do not require special preparation before gas-dynamic spraying. However, blast-abrasive (sandblasting) surface preparation for spraying increases the adhesion strength of coating to substrate. It can be performed on equipment for gas-dynamic spraying, for example, using K-00-04-16, other abrasive powder, or sand. In this case, the particle size of the powder should not exceed $0.2 \mathrm{~mm}$.

For supersonic gas-dynamic spraying of powder materials on the surface of mounting holes, a commercial system for gas-dynamic spraying "DIMET-403" was used. It is advisable to use A-80-13 as a powder material recommended for shields restoration made of aluminum alloys. 
It should be noted that the use of gas-dynamic spraying makes it possible to compensate parts wear up to several millimeters per side $(2-4 \mathrm{~mm})$. In this case, the powder was applied to the surface of the part without any bond coating.

To strengthen the holes repaired by gas-dynamic spraying (after their boring on a lathe), a set of equipment for $\mathrm{MAO}$ was used. With $\mathrm{MAO}$, it is advisable to use alkaline electrolyte with water glass additives of the following concentration of components, $\mathrm{g} / \mathrm{l}$ : potassium hydroxide $(\mathrm{KOH})-2.9 \ldots 3$; liquid glass $\left(\mathrm{Na}_{2} \mathrm{SiO}_{3}\right)-4 \ldots 6$.

Due to the fact that MAO provides the formation of a hardened layer not only inward but also outward increasing the part's linear dimensions (with formation of an outer friable layer), shields strengthening should be carried out with allowance for finish machining (at least $0.05 \ldots 0.07 \mathrm{~mm}$ per side) (Figure 11).

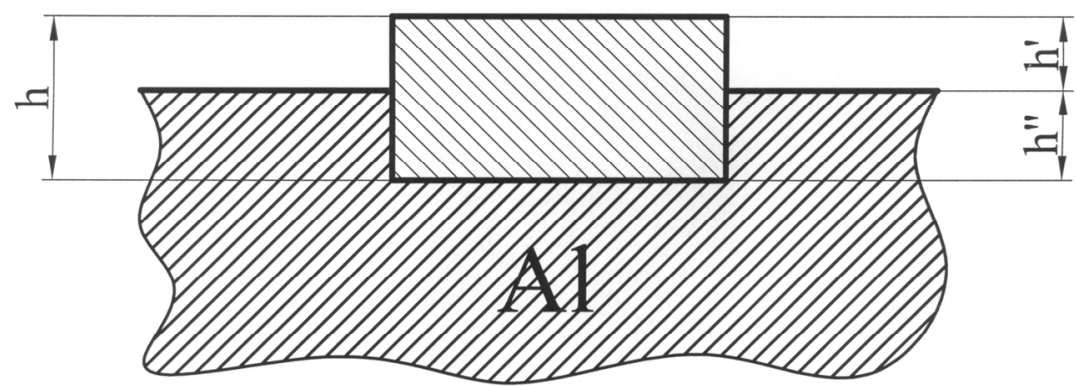

Figure 11. General scheme for the formation of an oxide-ceramic coating (h), an outer loose layer and a modified base layer during MAO of aluminum alloys.

It should be noted that an increase in the thickness of the outer loose layer occurred due to the components of sodium metasilicate contained in the electrolyte ( $\mathrm{SiO}$ cations), which under the action of microarc discharges were included in the coating.

To remove the outer friable layer of the coating after MAO (finish machining), it is recommended to use an elastic abrasive tool consisting of abrasive paper petals fixed between two discs. After finish machining of the coating, the thickness of the hardened layer should be at least $0.12 \ldots 0.14 \mathrm{~mm}$. The indicated values were in good agreement with the data of various researchers, who recommend maintaining the thickness of the hardened layer in the range of $0.5 \ldots 0.1 \mathrm{~mm}$ to ensure the high wear resistance of coatings [24,34-36].

The general view of the restored bearing assembly of electric motor is shown in Figure 12.

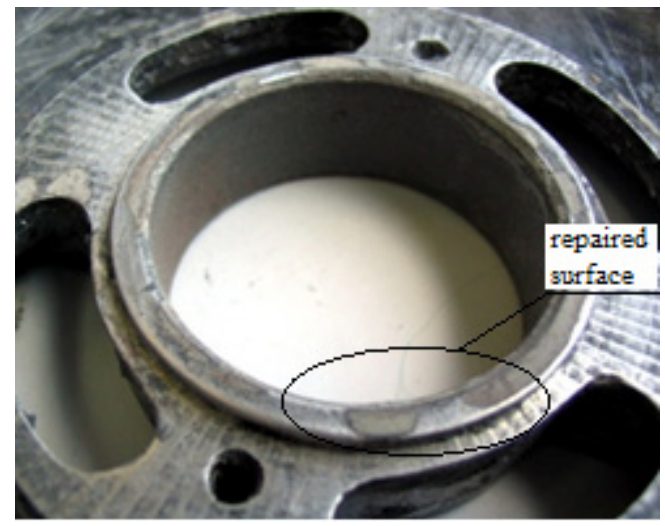

Figure 12. Coated bearing shield of an AD type electric motor.

\section{Conclusions}

The dependence of the adhesion of aluminum coatings in the process of gas-dynamic spraying of composite aluminum powders on the pressure and temperature of the gas 
flow, as well as on the fractional composition of the powders, was analyzed; optimal technological parameters were recommended.

Rational modes of formation of hardened ceramic coatings for the restoration of aluminum products used in mechanical engineering were recommended.

On the basis of tribological tests, it was practically shown that the strengthening of aluminum coatings by the method of MAO can significantly increase their wear resistance.

Based on the above studies, it can be assumed that the service life of the bearing assembly of electric motors restored by gas-dynamic spraying with a new technology of MAO can be significantly increased under real operating conditions. The developed technology is recommended for implementation in repair, maintenance, or other technical services dealing with restoration and hardening of worn-out parts.

Author Contributions: Conceptualization, Y.K. and I.K.; formal analysis, D.G., V.D. (Vadim Davydov) and A.M.; investigation, Y.K., M.M. and I.K.; visualization, A.B. and Y.K., writing-original draft preparation, Y.K. and I.K.; writing-review and editing, A.B., V.D. (Vadim Davydov), V.D. (Valentin Dudkin) and A.M. All authors have read and agreed to the published version of the manuscript.

Funding: The research was partially funded by the Ministry of Science and Higher Education of the Russian Federation under the strategic academic leadership program 'Priority 2030' (Agreement 075-15-2021-1333 dated 30 September 2021). The research was partially funded by the Russian Science Foundation in the priority area of activity of the Russian Science Foundation "Conducting fundamental scientific research by small individual scientific groups" (Agreement No. 22-29-00800). Experimental studies were performed on the equipment in the Shared Use Centre entitled "Composition, structure and properties of structural and functional materials" of the NRC «Kurchatov Institute»-CRISM "Prometey" with the financial support of the state represented by the Ministry of Education and Science of the Russian Federation under the Agreement No. 13.CKP.21.0014 (075-11-2021-068). The unique identifier is RF-2296.61321X0014.

Conflicts of Interest: The authors declare no conflict of interest.

\section{References}

1. Iftikhar, M.H.; Park, B.-G.; Kim, J.-W. Design and Analysis of a Five-Phase Permanent-Magnet Synchronous Motor for FaultTolerant Drive. Energies 2021, 14, 514. [CrossRef]

2. Gizatullin, B.; Gafurov, M.; Vakhin, A.; Mattea, C.; Stapf, S. Native Vanadyl Complexes in Crude Oil as Polarizing Agents for in Situ Proton Dynamic Nuclear Polarization. Energy Fuels 2019, 33, 10923. [CrossRef]

3. Alekseev, P.N.; Blandinskii, V.Y.; Balanin, A.L.; Shepelev, S.F.; Shirokov, A.V. Efficiency Assessment of Nuclear Energy Development Scenarios for Russia Using Multi-Criteria Analysis. At. Energy 2020, 128, 43. [CrossRef]

4. Barsi, D.; Costa, C.; Satta, F.; Zunino, P.; Sergeev, V. Feasibility of mini combined cycles for naval applications. MATEC Web Conf. 2018, 245, 07008. [CrossRef]

5. Klinov, D.A.; Gulevich, A.V.; Kagramanyan, V.S.; Dekusar, V.M.; Usanov, V.I. Development of Sodium-Cooled Fast Reactors Under Modern Conditions. Challenges and Stimuli. At. Energy 2019, 125, 143. [CrossRef]

6. Davydov, V.V.; Myazin, N.S.; Kiryukhin, A.V. Nuclear-Magnetic Flowmeter-Relaxometers for Monitoring Coolant and Feedwater Flow and Status in Npp. At. Energy 2020, 127, 274. [CrossRef]

7. Zamudio-Ramirez, I.; Osornio-Rios, R.A.; Trejo-Hernandez, M.; Romero-Troncoso, R.d.J.; Antonino-Daviu, J.A. Smart-Sensors to Estimate Insulation Health in Induction Motors via Analysis of Stray Flux. Energies 2019, 12, 1658. [CrossRef]

8. Nakamura, H.; Mizuno, Y. Method for Diagnosing a Short-Circuit Fault in the Stator Winding of a Motor Based on Parameter Identification of Features and a Support Vector Machine. Energies 2020, 13, 2272. [CrossRef]

9. Cavaliere, P. Cold-Spray Coatings, Recent Trends and Future Perspectives; Springer International Publishing AG: Cham, Switzerland, 2018.

10. Kuznetsov, Y.A.; Kravchenko, I.N. A study of the mechanism of interaction between particlesand metal substrate at supersonic gas dynamic cold spraying. Polym. Science. Ser. D 2020, 13, 89. [CrossRef]

11. Rech, S.; Trentin, A.; Vezzu, S.; Vedelago, E.; Legoux, J.-G.; Irissou, E. Different Cold Spray Deposition Strategies: Single- and Multi-layers to Repair Aluminium Alloy Components. J. Therm. Spray Technol. 2014, 23, 1237-1250. [CrossRef]

12. Cavaliere, P.; Silvello, A. Crack Repair in Aerospace Aluminum Alloy Panels by Cold Spray. J. Therm. Spray Technol. 2017, 26, 661-670. [CrossRef]

13. Yin, S.; Cavaliere, P.; Aldwell, B.; Jenkins, R.; Liao, H.; Li, W.; Lupoi, R. Cold spray additive manufacturing and repair: Fundamentals and applications. Addit. Manuf. 2018, 21, 628-650. [CrossRef]

14. Tushinsky, L.I.; Alkhimov, A.P.; Kosarev, V.F.; Plokhov, A.V.; Mochalina, N.S. Investigation of general corrosion of metal coatings applied by cold gas-dynamic spraying. Met. Process. (Technol. Equip. Tools) 2006, 4, 23-25. 
15. Bobkova, T.I.; Vasiliev, A.F.; Prudnikov, I.S.; Farmakovsky, B.V. Functional-gradient coatings obtained using supersonic cold gas-dynamic spraying. Vopr. Materialoved. 2019, 1, 74-78. [CrossRef]

16. Shtol, Y.L.; Dudko, V.S. Prospects for the use of cold gas-dynamic spraying in repair production. Repair. Recovery Mod. 2012, 9 , $48-53$.

17. Lee, H.Y.; Yu, Y.H.; Lee, Y.C.; Hong, Y.P.; Ko, K.H. Thin Film Coatings of WO3 by Cold Gas Dynamic Spray: A Technical Note. J. Therm. Spray Technol. 2015, 14, 183. [CrossRef]

18. Gerashchenkov, D.A.; Makarov, A.M.; Bystrov, R.Y.; Bobkova, T.O.; Belyakov, A.N.; Bykova, A.D.; Markov, M.A.; Farmakovsky, B.V. Technological aspects of obtaining functional gradient coatings to protect machinery from wear. Key Eng. Mater. 2019, 822, 768. [CrossRef]

19. Wen, L.; Wang, Y.; Jin, Y.; Liu, B.; Zhou, Y.; Sun, D. Microarc oxidation of $2024 \mathrm{Al}$ alloy using spraying polar and its influence on microstructure and corrosion behavior. Surf. Coat. Technol. 2013, 228, 92-99. [CrossRef]

20. Tran, Q.-P.; Kuo, Y.-C.; Sun, J.-K.; He, J.-L.; Chin, T.-S. High quality oxide-layers on Al-alloy by micro-arc oxidation using hybrid voltages. Surf. Coat. Technol. 2016, 303, 61-67. [CrossRef]

21. Kuznetsov, Y.A.; Kravchenko, I.N.; Goncharenko, V.V.; Glinskii, M.A. Machining of the ceramic oxide coating formed by plasma electrolytic oxidation. Russ. Metall. (Met.) 2018, 13, 82-86. [CrossRef]

22. Kossenko, A.; Kuznetsov, Y.; Zinigrad, M. Combined technology of repairing and hardening of machine parts. In The Optimization of Composition, Structure and Properties of Metals, Oxides, Composites, Nano and Amorphous Materials Bi-National Russia-Israel Workshop; Academy service center of the Ural Branch of Russian Academy of Science Pern: Perm, Russia, 2008; pp. 78-90.

23. Kuznetsov, Y.A. Combined technology of production of ceramic coatings. Weld. Int. 2005, 19, 894-896. [CrossRef]

24. Kuznetsov, Y.A.; Markov, M.A.; Krasikov, A.V.; Bystrov, R.Y.; Belyakov, A.N.; Bykova, A.D.; Makarov, A.M.; Fadin, Y.A. Formation of wear- and corrosion-resistant ceramic coatings by combined technologies of spraying and micro-arc oxidation. Russ. J. Appl. Chem. 2019, 92, 875-882. [CrossRef]

25. Kolomeichenko, A.V. Technologies for Increasing the Durability of Machine Parts by Restoration and Hardening of Working Surfaces by Combined Methods Using Micro-Arc Oxidation: Monograph; Publishing house Orel GAU: Orel, Russia, 2013 ; p. 230.

26. Kolomeichenko, A.V.; Kuznetsov, Y.A.; Logachev, V.N.; Titov, N.V.; Sharifullin, S.N. Increase of the resource of machine parts working by combined methods using plasma electrolytic oxidation. J. Phys. 2018, 1058, 012074. [CrossRef]

27. Chernyshov, N.S. Internal stresses in parts made of AK9ch aluminum alloy recovered by soldering using PA-12 solder. Agrotech Energy Supply 2014, 1, 155-159.

28. Kuznetsov, Y.A.; Mityureva, N.V. Grinding of parts made of aluminum alloys hardened by micro-arc oxidation. Strength. Technol. Coat. 2010, 2, 38-40.

29. Neronov, Y.I.; Seregin, N.N. Development and Study of a Pulsed Magnetic Induction Meter Based on Nuclear Magnetic Resonance for High Magnetic Fields. Meas. Tech. 2017, 60, 818-822. [CrossRef]

30. D'yachenko, S.V.; Zhernovoi, A.I. The Langevin formula for describing the magnetization curve of a magnetic liquid. Tech. Phys. 2016, 61, 1835-1837. [CrossRef]

31. Myazin, N.S. Features of formation of structure of a nuclear magnetic resonance signal in weak magnetic field. J. Phys. Conf. Ser. 2018, 1135, 012061. [CrossRef]

32. Livshits, S.A.; Yudina, N.A.; Novikova, O.V.; Katz, D.B.; Nagornov, V.N. Determination of the conditions of spontaneous combustion of a rheologically complex medium inside the continuous infinite cylinder in convective heat transfer case. E3S Web Conf. 2019, 124, 01034. [CrossRef]

33. Larionova, T.V.; Yunusov, F.A.; Bobrynina, E.V.; Koltsova, T.S.; Tolochko, O.V. Fullerene Soot-Reinforced Al-Based Composites and Their Densification via Copper Addition. J. Mater. Eng. Perform. 2020, 29, 5195-5202. [CrossRef]

34. Naumova, E.A.; Makushina, M.A.; Tsirkov, P.A. Investigation of the structure and properties of wear-resistant coatings obtained by micro-arc oxidation on alloys of the AL-CA-SC systems. Proc. GOSNITI 2015, 120, 122-124.

35. Komarov, A.I.; Romanyuk, A.S.; Zolotaya, P.S.; Goransky, G.G.; Vaganov, V.V. Increasing the hydroabrasive resistance of products by combining the methods of cold gas-dynamic spraying and micro-arc oxidation. Top. Issues Mech. Eng. 2019, 8, $343-347$.

36. Boytsov, B.V.; Lesnevsky, L.N.; Lyakhovetsky, M.A.; Petukhov, Y.V.; Pruss, E.M.; Troshin, A.E.; Ushakov, A.M. Improving the reliability of aluminum molds by protecting them from wear and corrosion by micro-arc oxidation. Probl. Mech. Eng. Mach. Reliab. 2013, 6, 45-53. 